\title{
RAPD and barcode analyses of groupers of the genus Epinephelus
}

\author{
K. Noikotr ${ }^{1}$, A. Chaveerach ${ }^{1}$, K. Pinthong ${ }^{2}$, A. Tanomtong ${ }^{1}$, R. Sudmoon ${ }^{1}$ \\ and T. Tanee ${ }^{3}$ \\ ${ }^{1}$ Department of Biology, Faculty of Science, Khon Kaen University, \\ Khon Kaen, Thailand \\ ${ }^{2}$ Deparment of Fundamental Science, Faculty of Science and Technology, \\ Surindra Rajabhat University, Surin, Thailand \\ ${ }^{3}$ Faculty of Environment and Resource Studies, Mahasarakham University, \\ Mahasarakham, Thailand
}

Corresponding author: $\mathrm{T}$. Tanee

E-mail: tawatchai5@hotmail.com

Genet. Mol. Res. 12 (4): 5721-5732 (2013)

Received March 14, 2013

Accepted September 16, 2013

Published November 18, 2013

DOI http://dx.doi.org/10.4238/2013.November.18.21

\begin{abstract}
The diversity of Epinephelus species was investigated throughout Thailand. Random amplified polymorphic DNA successfully produced 1300 bands that were phylogenetically informative and used to construct cladograms. Values of pairwise genetic similarity (S) within species ranged from 0.65 in E. erythrurus to 0.99 in E. malabaricus. The interspecific values of S ranged from 0.23 between $E$. malabaricus and $E$. bleekeri to 0.66 between E. coeruleopunctatus and E. erythrurus. The intraspecific nucleotide variation ranged from 0.037 to 0.159 in the mitochondrially encoded 16S RNA (MT-RNR2) region and from 0.003 to 0.157 for the mitochondrially encoded cytochrome $\mathrm{c}$ oxidase I (MT-CO1) region. All sequences were submitted individually to GenBank. The barcode sequences of Thai species of Epinephelus were aligned to the same species found in GenBank. For the MT-RNR2 gene region, intraspecific nucleotide variation ranged from 0.000 to 0.121 , and interspecific nucleotide variation ranged from 0.003 to 0.146 . For
\end{abstract}


the MT-CO1 gene region, intraspecific nucleotide variation ranged from 0.000 to 0.140 , and interspecific nucleotide variation ranged from 0.000 to 0.166 . The MT-RNR2 data indicate that some species, including E. bleekeri from India and E. malabaricus from Thailand are not monophyletic. Additionally, the MT-CO1 data indicated that $E$. bleekeri, E. quoyanus and E. coeruleopunctatus are not monophyletic. The sequences of E. lanceolatus from each country are highly conserved, with genetic distances ranging from 0.000 to 0.003 . Another important result from this study is that the barcode sequence from Thai E. erythrurus was previously not present in the GenBank.

Key words: Epinephelidae; Epinephelinae; DNA Fingerprint; Groupers; Serranidae; Systematics; Barcodes

\section{INTRODUCTION}

Epinephelus is the largest genus of groupers in the family Serranidae, with approximately 100 species inhabiting marine habitats worldwide. They have been used not only as a food resource but also as captive exhibits in aquariums. Many species are important in both the fishing and marine aquaculture industries. In Thailand, groupers are found throughout the Gulf of Thailand and the Andaman Sea. The high value of groupers has led to them being over-harvested from their natural habitat, which correlates with a reduction in their marine capture rates in recent years. As a consequence, coastal aquaculture of groupers has been promoted by government organizations, and many species have proliferated successfully, such as E. coioides, E. fuscoguttatus, E. lanceolatus, E. malabaricus, and E. tauvina.

Reports of the species diversity of groupers in Thailand are incomplete and inconclusive. For example, Suvatti (1950) reported 20 species of epinephelid fishes in Thailand. Duangsawasdi (1964) reported 25 species and five genera of epinephelid fishes found along the coast of Thailand. Fifteen of these species were not included in Suvatti's report, whereas seven reported by Suvatti (1950) were not included by Duangsawasdi (1964). Banasopit (1968) reported 29 grouper species and seven genera in Thai waters from an analysis of various documents, and found that there was much confusion regarding the common and scientific names and their identification in photographs. A query of fishbase.org (Froese and Pauly, 2012) reported 42 grouper species recorded from Thailand, including 25 species of the genus Epinephelus.

Groupers are identified mainly by morphological characteristics, such as body configuration, size and number of body parts, and color patterns. However, there is much overlap in the morphological traits, especially in color pattern, and this can lead to misidentification. Molecular techniques have been used for systematics in many groups of organisms, including fishes. The random amplified polymorphic DNA (RAPD) technique allows the detection of DNA polymorphisms by randomly amplifying multiple regions of the genome using the polymerase chain reaction (PCR) and short single degenerate primers. RAPD markers have been used to investigate the taxonomic status of different groups of fishes, such as tilapia (Bardakci and Skibinski, 1994), Atlantic Coast striped bass (Bielawski and Pumo, 1997), barb fish of the 
genus Barbus from the Iberian Peninsula (Callejas and Ochando, 2001), clown fish (Jayasankar, 2004), and groupers (Govindaraju and Jayasankar, 2004; Koedprang et al., 2007). DNA barcoding can serve as a means of assessing systematic information and can assist the identification of species, resulting in more rapid and accurate identification of juveniles, individuals at different life stages, incomplete specimens, and members of more cryptic species. Many studies have used several standard genomic regions for barcoding. Hebert et al. (2004) used the mitochondrially encoded cytochrome c oxidase I (MT-CO1) to discriminate between bird species. Ward et al. (2008) used MT-CO1 to distinguish two different species of sea bass from Australia and Myanmar. DNA barcoding of Indian marine fishes using MT-CO1 was reported for the first time by Lakra et al. (2011). The average Kimura two-parameter (K2P) distances within species, genera, families, and orders were $0.30,6.60,9.91$, and $16.00 \%$, respectively. Sachithanandam et al. (2012) used MT-CO1 barcodes to distinguish three Epinephelus species, E. longispinis, E. ongus, and E. areolatus. Zhang and Hanner (2012) studied sequences of MT-CO1, mitochondrially encoded 16S RNA (MT-RNR2), mitochondrially encoded cytochrome b (MT-CYB), and RNA 18S ribosomal (RNA18S) in 242 species of fish, including the following 11 Epinephelus species: E. amblycephalus, E. areolatus, E. bleekeri, E. coioides, E. epistictus, E. fasciatomaculosus, E. maculatus, E. poecilonotus, E. sexfasciatus, E. spilotoceps, and Epinephelus sp. Several barcode sequences found in online databases indicate that species of Epinephelus from many countries have also been studied.

This research applied RAPD banding patterns to study the systematics of Epinephelus in Thailand. DNA barcodes were also defined for use as species-specific markers for more rapid identification of Thai Epinephelus. Additionally, genetic distances were compared between species from Thailand and species from other localities.

\section{MATERIALS AND METHODS}

\section{Sample collection and DNA extraction}

Multiple species of Epinephelus were collected from various sources, including artisanal fisheries, seafood markets, marine aquariums, and marine fishery stations in the Thai provinces of Chantaburi and Samuthsakorn, eastern Thailand, belonged to the Gulf of Thailand; Phanga and Phuket, southern Thailand, belonged to Andaman Sea. Species were identified based on morphological characters according to Heemstra and Randall (1993). Tissue samples for DNA extraction were collected by clipping small pieces from the caudal fin, which were then preserved in $100 \%$ ethanol and stored at $-20^{\circ} \mathrm{C}$.

Genomic DNA was extracted from the fin samples using a Genomic DNA Extraction Kit for tissues (RBC Bioscience). The presence of DNA was assessed by electrophoresis using a $0.8 \%$ agarose gel, which was stained with ethidium bromide. The quality and quantity of DNA was determined using a gel-documenting instrument (Gel Doc 2000, BIO-RAD). The DNA samples were then diluted to a final concentration of $20 \mathrm{ng} / \mu \mathrm{L}$ and used as a template for PCR.

\section{RAPD fingerprinting}

PCR was carried out in a total volume of $25 \mu \mathrm{L}$, consisting of GoTaq Green Master 
Mix (Promega), $0.5 \mu \mathrm{M}$ primer, and $20 \mathrm{ng}$ DNA template. The reaction mixture was denatured at $94^{\circ} \mathrm{C}$ for $1 \mathrm{~min}$ and amplification was performed with the following 35 thermal cycles: denaturation for $30 \mathrm{~s}$ at $94^{\circ} \mathrm{C}$, annealing for $40 \mathrm{~s}$ at $40^{\circ} \mathrm{C}$, and extension for $40 \mathrm{~s}$ at $72^{\circ} \mathrm{C}$, followed by a $5 \mathrm{~min}$ final extension at $72^{\circ} \mathrm{C}$. Thirty-five degenerate primers were screened, and the 12 successful primer sequences (5'-3') were: CAATCGCCGT, GTTGCGATCC, GGACCCTTAC, TCAGTCCGGG, AGGTCTTGGG, CCCCAACAAC, TTCCAGCTGC, CCGCAGCCAA, AGCCAGCGAA, CGGCCCCGGT, CACAGGTCAC, and GTGATCGCAG. The amplified products were detected by electrophoresis using a 1.2\% agarose gel in TAE buffer and were visualized with ethidium bromide staining. For all of the successful primers, the presence (1) or absence (0) of a fragment was scored. The index of similarity between all possible pairwise comparisons was calculated using the DICE coefficient formula (Dice, 1945; Sneath and Sokal, 1973). Phylogenetic relationships were reconstructed by UPGMA cluster analysis using the program NTSYSpc 2.10p (Rohlf, 1998).

\section{DNA barcoding}

DNA barcoding was done with following primer pairs (5'-3') CGCCTGTTTATCAAA AACAT and CCGGTCTGAACTCAGATCACGT for the MT-RNR2 region and TGTAAAA CGACGCCAGTCAACCAACCACAAAGACATTGGCACandCAGGAAACAGCTATGAC ACCTCAGGGTGTCCGAARAAYCARAA for the MT-CO1 region (Ivanova et al., 2007). Reactions were carried out in a total volume of $30 \mu \mathrm{L}$ consisting of GoTaq Green Master Mix (Promega), $0.25 \mu \mathrm{M}$ primer (each), and $20 \mathrm{ng}$ DNA template. The reaction mixture was incubated at $94^{\circ} \mathrm{C}$ for 2 min and amplification was performed with the following 35 thermal cycles: denaturation for $30 \mathrm{~s}$ at $94^{\circ} \mathrm{C}$, annealing for $40 \mathrm{~s}$ at $52^{\circ} \mathrm{C}$, and extension for $1 \mathrm{~min}$ at $72^{\circ} \mathrm{C}$, followed by a $10 \mathrm{~min}$ final extension at $72^{\circ} \mathrm{C}$. The specific amplified fragments were then sequenced, and the sequences were annotated by using BLAST (NCBI, 2013), MEGA5 (Tamura et al., 2011) and Artemis (Rutherford et al., 2000). The annotated sequences were then submitted to GenBank. Additionally, the barcode sequences of the Thai species of Epinephelus were aligned with sequences of the same Epinephelus species from other countries.

\section{RESULTS}

Eight species of Epinephelus from Thailand were studied: E. bleekeri, E. coeruleopunctatus, E. coioides, E. erythrurus, E. fuscoguttatus, E. lanceolatus, E. malabaricus, and E. quoyanus. Two individuals from each species were collected from different areas, and two individuals of Cephalopholis formosa were included as an outgroup in the RAPD analysis.

RAPD fingerprinting data were used for phylogenetic analysis. The banding patterns (Figure 1) produced a total of 1300 bands generated from 12 primers that were successfully screened from 35 primers. The cladogram (Figure 2) constructed from these discrete bands can be used to differentiate each pair of individuals of one species from those of another species, to group members of the same species together and to separate the ingroup from the outgroup. Pairwise genetic similarity (S) values at intraspecific levels ranged from 0.65 in E. erythrurus to 0.99 in E. malabaricus. The interspecific $\mathrm{S}$ values ranged from 0.23 between E. malabaricus and E. bleekeri to 0.66 between E. coeruleopunctatus and E. erythrurus (Table 1). 


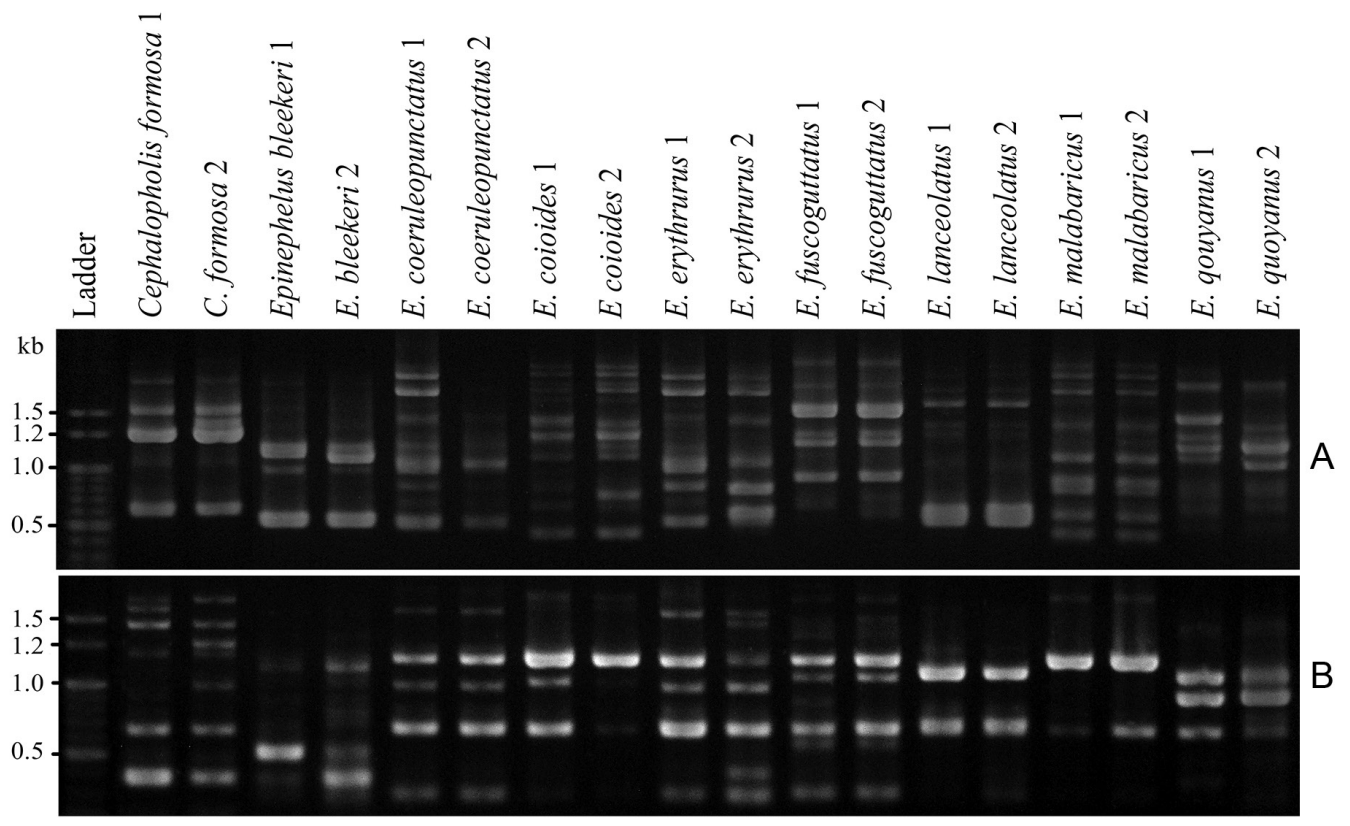

Figure 1. An example of RAPD banding patterns from eight Epinephelus species and the outgroup using the primers CGGCCCCGGT (A) and AGGTCTTGGG (B)

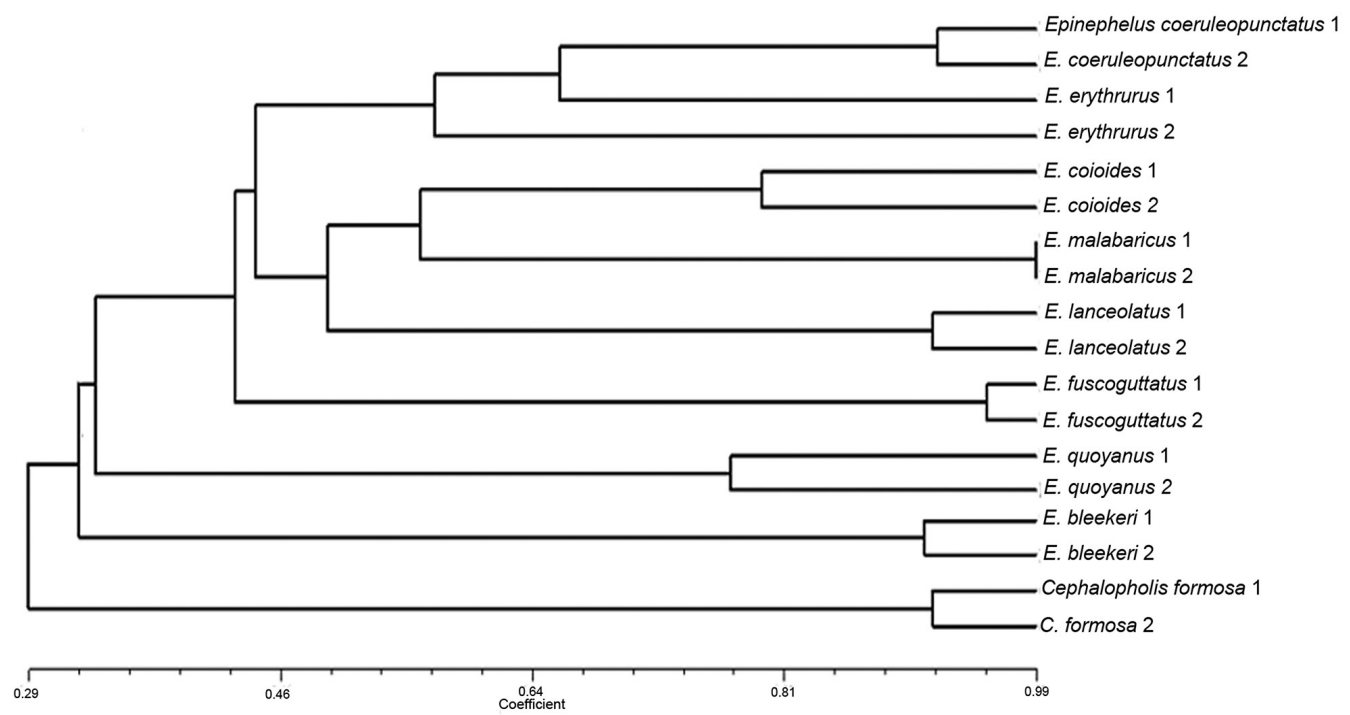

Figure 2. Cladogram resulting from the NTSYSpc2.10p analysis of all species studied of Epinephelus based on RAPD bands from 12 primers. 
Table 1. Similarity coefficients for eight Epinephelus species analyzed by RAPD fingerprint data from 12 primers.

\begin{tabular}{|c|c|c|c|c|c|c|c|c|c|c|c|c|c|c|c|c|c|c|}
\hline & 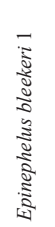 & 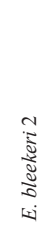 & 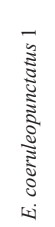 & 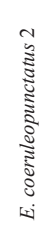 & 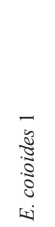 & 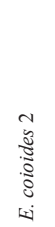 & 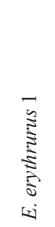 & 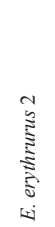 & 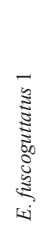 & 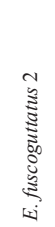 & 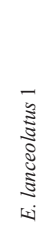 & 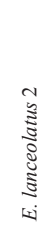 & 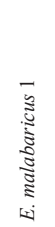 & 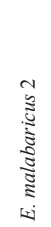 & 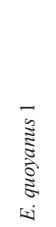 & 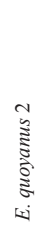 & 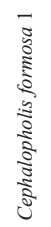 & 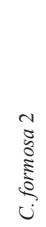 \\
\hline E. bleekeri 1 & 1.00 & & & & & & & & & & & & & & & & & \\
\hline E. bleekeri 2 & 0.91 & 1.00 & & & & & & & & & & & & & & & & \\
\hline E. coeruleopunctatus 1 & 0.42 & 0.39 & 1.00 & & & & & & & & & & & & & & & \\
\hline E. coeruleopunctatus 2 & 0.43 & 0.39 & 0.92 & 1.00 & & & & & & & & & & & & & & \\
\hline E. coioides 1 & 0.33 & 0.32 & 0.51 & 0.46 & 1.00 & & & & & & & & & & & & & \\
\hline E. coioides 2 & 0.35 & 0.33 & 0.43 & 0.44 & 0.80 & 1.00 & & & & & & & & & & & & \\
\hline E. erythrurus 1 & 0.31 & 0.30 & 0.65 & 0.66 & 0.45 & 0.57 & 1.00 & & & & & & & & & & & \\
\hline E. erythrurus 2 & 0.37 & 0.35 & 0.53 & 0.54 & 0.47 & 0.48 & 0.65 & 1.00 & & & & & & & & & & \\
\hline E. fuscoguttatus 1 & 0.33 & 0.33 & 0.42 & 0.44 & 0.45 & 0.45 & 0.48 & 0.45 & 1.00 & & & & & & & & & \\
\hline E. fuscoguttatus 2 & 0.33 & 0.34 & 0.39 & 0.41 & 0.43 & 0.48 & 0.48 & 0.41 & 0.95 & 1.00 & & & & & & & & \\
\hline E. lanceolatus 1 & 0.31 & 0.27 & 0.37 & 0.35 & 0.41 & 0.48 & 0.46 & 0.52 & 0.42 & 0.43 & 1.00 & & & & & & & \\
\hline E. lanceolatus 2 & 0.34 & 0.32 & 0.39 & 0.37 & 0.39 & 0.49 & 0.49 & 0.50 & 0.46 & 0.47 & 0.92 & 1.00 & & & & & & \\
\hline E. malabaricus 1 & 0.27 & 0.23 & 0.37 & 0.36 & 0.49 & 0.63 & 0.50 & 0.50 & 0.39 & 0.41 & 0.56 & 0.54 & 1.00 & & & & & \\
\hline E. malabaricus 2 & 0.27 & 0.23 & 0.37 & 0.37 & 0.50 & 0.62 & 0.50 & 0.50 & 0.39 & 0.41 & 0.56 & 0.55 & 0.99 & 1.00 & & & & \\
\hline E. quoyanus 1 & 0.34 & 0.33 & 0.27 & 0.32 & 0.37 & 0.36 & 0.32 & 0.33 & 0.39 & 0.35 & 0.38 & 0.36 & 0.45 & 0.45 & 1.00 & & & \\
\hline E. quoyanus 2 & 0.29 & 0.28 & 0.24 & 0.26 & 0.30 & 0.29 & 0.26 & 0.25 & 0.33 & 0.30 & 0.34 & 0.33 & 0.40 & 0.41 & 0.78 & 1.00 & & \\
\hline C. formosa 1 & 0.22 & 0.23 & 0.31 & 0.34 & 0.28 & 0.27 & 0.32 & 0.29 & 0.33 & 0.32 & 0.28 & 0.27 & 0.24 & 0.23 & 0.32 & 0.26 & 1.00 & \\
\hline C. formosa 2 & 0.28 & 0.28 & 0.32 & 0.34 & 0.28 & 0.29 & 0.35 & 0.35 & 0.31 & 0.30 & 0.30 & 0.28 & 0.26 & 0.25 & 0.32 & 0.27 & 0.92 & 1.00 \\
\hline
\end{tabular}

DNA fragments from regions of MT-RNR2 and MT-CO1 were successfully amplified for all of the Epinephelus species. These fragments were sequenced, and then the nucleotide sequences were used for alignment and to construct dendrograms (Figures 3 and 4); this identified that the levels of interspecific sequence variations were from 0.037 to 0.159 for MTRNR2 (Table 2) and 0.003 to 0.157 for MT-CO1 (Table 3). GenBank accession numbers of all sequences were shown in Table 4. The barcodes for MT-RNR2 and MT-CO1 from the Thai $E$. erythrurus were previously absent from the GenBank.

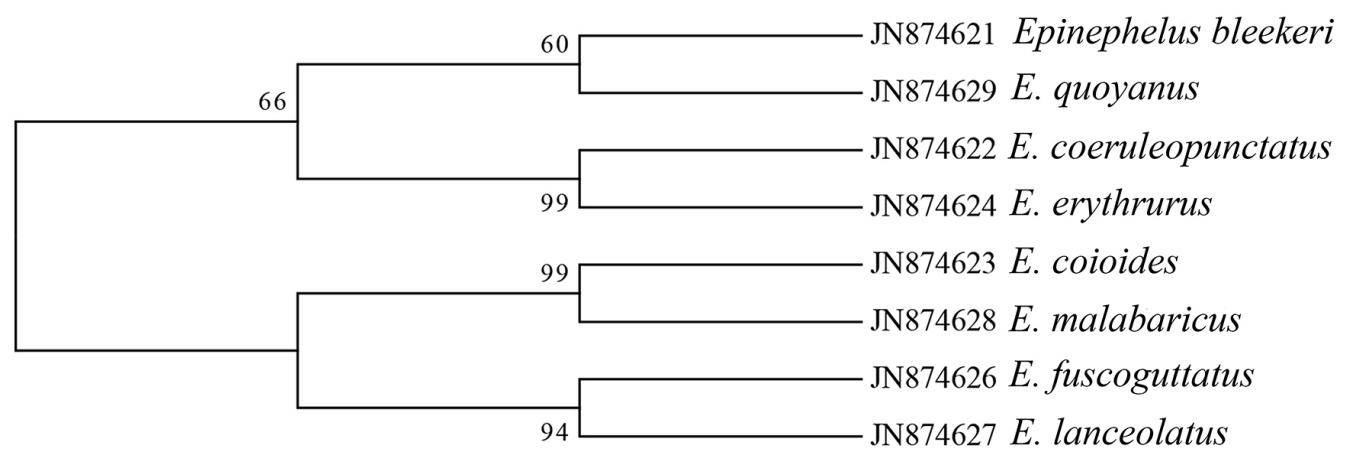

Figure 3. Dendrogram based on MT-RNR2 sequences of eight species of Epinephelus from Thailand.

Sequence alignments and dendrograms of the eight Epinephelus species from Thailand and other countries using MT-RNR2 and MT-CO1 data are shown in Figures 5 and 6. Intraspecific genetic distances for MT-RNR2 ranged from 0.000 for pairs of E. coioides (AY947608 and JF750751, DQ154105 and JF750751, DQ154105 and AY947608), E. lanceolatus (HQ660062 
and AY947588), E. malabaricus (AY947609 and DQ067309), and E. quoyanus (DQ067313 and JF750757, AY731073 and JF750757, AY731073 and DQ067313) to 0.121 for a pair of E. fuscoguttatus (AY947561 and JN874626). Whereas, interspecific genetic distances ranged from 0.003 between E. malabaricus (AJ496738) and E. bleekeri (AJ496736) to 0.146 between E. coioides (JN874623) and E. coeruleopunctatus (JN874622). Intraspecific genetic distances for MT-CO1 ranged from 0.000 between pairs of E. bleekeri (JN242646 and JX674973, JN021297 and JX674973, JN021297 and JN242646), E. lanceolatus (EF609351 and JQ268579, NC011715 and EF609351, NC011715 and JQ268579), and E. malabaricus (DQ107871 and GU804899, JF493446 and GU804899, JF493446 and DQ107871) to 0.140 between a pair of E. coeruleopunctatus (JQ349962 and JQ268574). Whereas, interspecific genetic distances ranged from 0.000 between E. quoyanus (JQ268583) and E. bleekeri (JX674973), E. quoyanus (JQ268583) and E. bleekeri (JN242646), E. quoyanus (JQ268583) and E. bleekeri (JN021297) to 0.166 between E. quoyanus (DQ107861) and E. malabaricus (JQ268580).

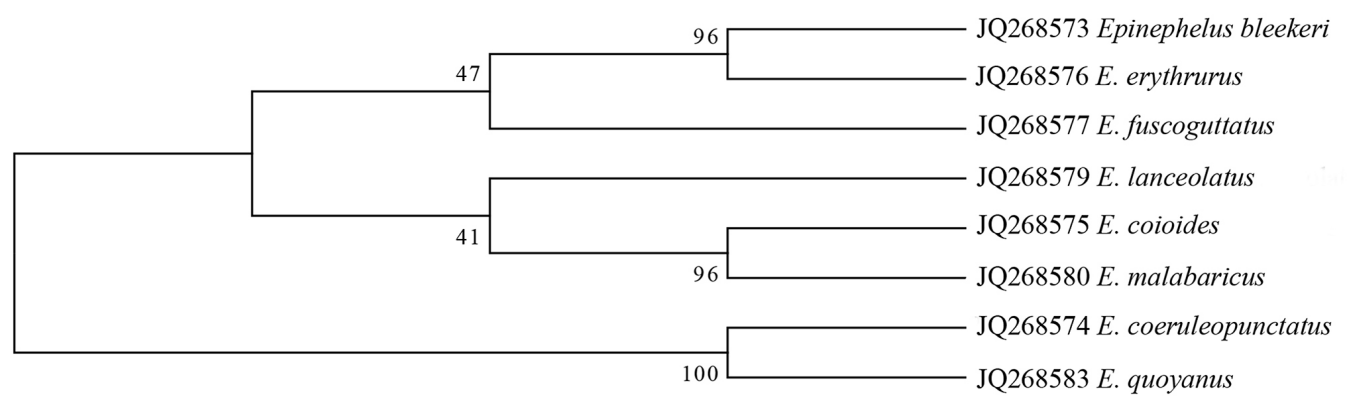

Figure 4. Dendrogram based on MT-CO1 sequences of eight species of Epinephelus from Thailand.

Table 2. Sequence variations/genetic distances of MT-RNR2 sequences from eight Epinephelus species from Thailand.

\begin{tabular}{|c|c|c|c|c|c|c|c|c|}
\hline & $\begin{array}{l}\text { JN874621 } \\
\text { E. bleekeri }\end{array}$ & $\begin{array}{c}\mathrm{JN} 874622 \\
\text { E. coeruleopunctatus }\end{array}$ & $\begin{array}{l}\mathrm{JN} 874623 \\
\text { E. coioides }\end{array}$ & $\begin{array}{c}\text { JN874624 } \\
\text { E. erythrurus }\end{array}$ & $\begin{array}{c}\text { JN874626 } \\
\text { E. fuscoguttatus }\end{array}$ & $\begin{array}{c}\text { JN874627 } \\
\text { E. lanceolatus }\end{array}$ & $\begin{array}{c}\text { JN874628 } \\
\text { E. malabaricus }\end{array}$ & $\begin{array}{c}\text { JN874629 } \\
\text { E. quoуапиs }\end{array}$ \\
\hline JN874621 Epinephelus bleekeri & - & & & & & & & \\
\hline JN874622 E. coeruleopunctatus & 0.086 & - & & & & & & \\
\hline JN874623 E. coioides & 0.115 & 0.110 & - & & & & & \\
\hline JN874624 E. erythrurus & 0.091 & 0.037 & 0.098 & - & & & & \\
\hline JN874626 E. fuscoguttatus & 0.128 & 0.112 & 0.099 & 0.115 & - & & & \\
\hline JN874627 E. lanceolatus & 0.137 & 0.129 & 0.118 & 0.126 & 0.097 & - & & \\
\hline JN874628 E. malabaricus & 0.159 & 0.143 & 0.081 & 0.132 & 0.146 & 0.155 & - & \\
\hline JN874629 E. quoуanus & 0.115 & 0.134 & 0.123 & 0.128 & 0.153 & 0.157 & 0.156 & - \\
\hline
\end{tabular}

Table 3. Sequence variations/genetic distances of MT-CO1 sequences from eight Epinephelus species from Thailand.

\begin{tabular}{|c|c|c|c|c|c|c|c|c|}
\hline & $\begin{array}{l}\text { JQ268573 } \\
\text { E. bleekeri }\end{array}$ & $\begin{array}{c}\mathrm{JQ} 268574 \\
\text { E. coeruleopunctatus }\end{array}$ & $\begin{array}{l}\text { JQ268575 } \\
\text { E. coioides }\end{array}$ & $\begin{array}{c}\text { JQ268576 } \\
\text { E. erythrurus }\end{array}$ & $\begin{array}{c}\text { JQ268577 } \\
\text { E. fuscoguttatus }\end{array}$ & $\begin{array}{c}\text { JQ268579 } \\
\text { E. lanceolatus }\end{array}$ & $\begin{array}{c}\text { JQ268580 } \\
\text { E. malabaricus }\end{array}$ & $\begin{array}{l}\text { JQ268583 } \\
\text { E. quoyanus }\end{array}$ \\
\hline JQ268573 Epinephelus bleekeri & - & & & & & & & \\
\hline JQ268574 E. coeruleopunctatus & 0.130 & - & & & & & & \\
\hline JQ268575 E. coioides & 0.122 & 0.139 & - & & & & & \\
\hline JQ268576 E. erythrurus & 0.008 & 0.126 & 0.116 & - & & & & \\
\hline JQ268577 E. fuscoguttatus & 0.103 & 0.149 & 0.106 & 0.106 & - & & & \\
\hline JQ268579 E. lanceolatus & 0.140 & 0.157 & 0.120 & 0.130 & 0.154 & - & & \\
\hline JQ268580 E. malabaricus & 0.126 & 0.136 & 0.032 & 0.119 & 0.106 & 0.126 & - & \\
\hline JQ268583 E. quoyanus & 0.133 & 0.003 & 0.138 & 0.129 & 0.149 & 0.157 & 0.135 & - \\
\hline
\end{tabular}




\section{Table 4. GenBank accession numbers for MT-RNR2 and MT-CO1 sequences from Epinephelus species.}

\begin{tabular}{lcc}
\hline Species & & Accession No. \\
\cline { 2 - 3 } & MT-RNR2 & MT-CO1 \\
\hline Epinephelus bleekeri & JN874621 & JQ268573 \\
E. coeruleopunctatus & JN874622 & JQ268574 \\
E. coioides & JN874623 & JQ268575 \\
E. erythrurus & JN874624 & JQ268576 \\
E. fuscoguttatus & JN874626 & JQ268578 \\
E. lanceolatus & JN874627 & JQ268579 \\
E. malabaricus & JN874628 & JQ268580 \\
E. quoyanus & JN874629 & JQ268583 \\
\hline
\end{tabular}

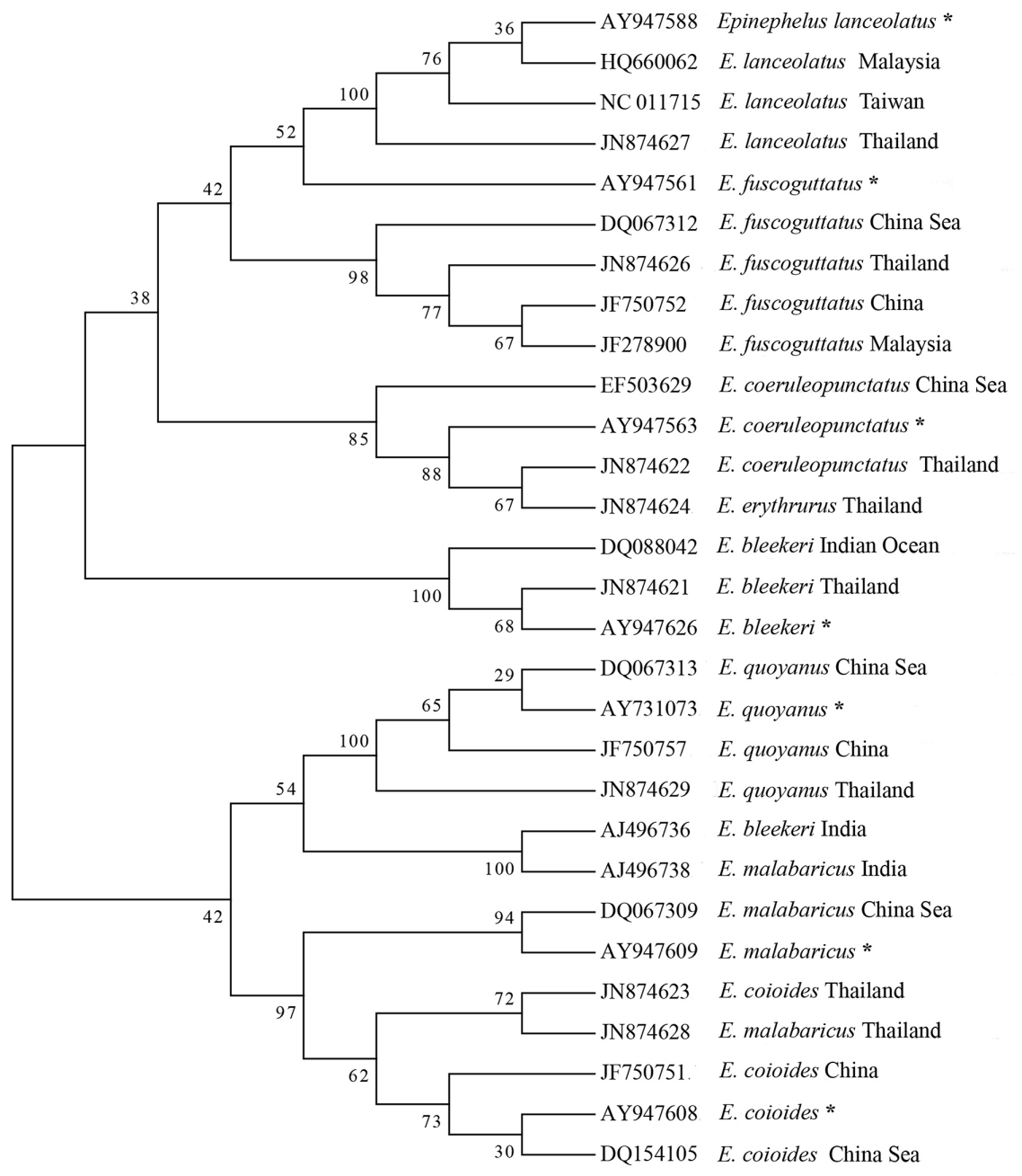

Figure 5. Dendrogram resulting from the MEGA5 analysis of Epinephelus species from Thailand and other countries based on MT-RNR2 sequence data. Bootstrap values are presented on the branches. No country was mentioned for accessions with asterisk. 


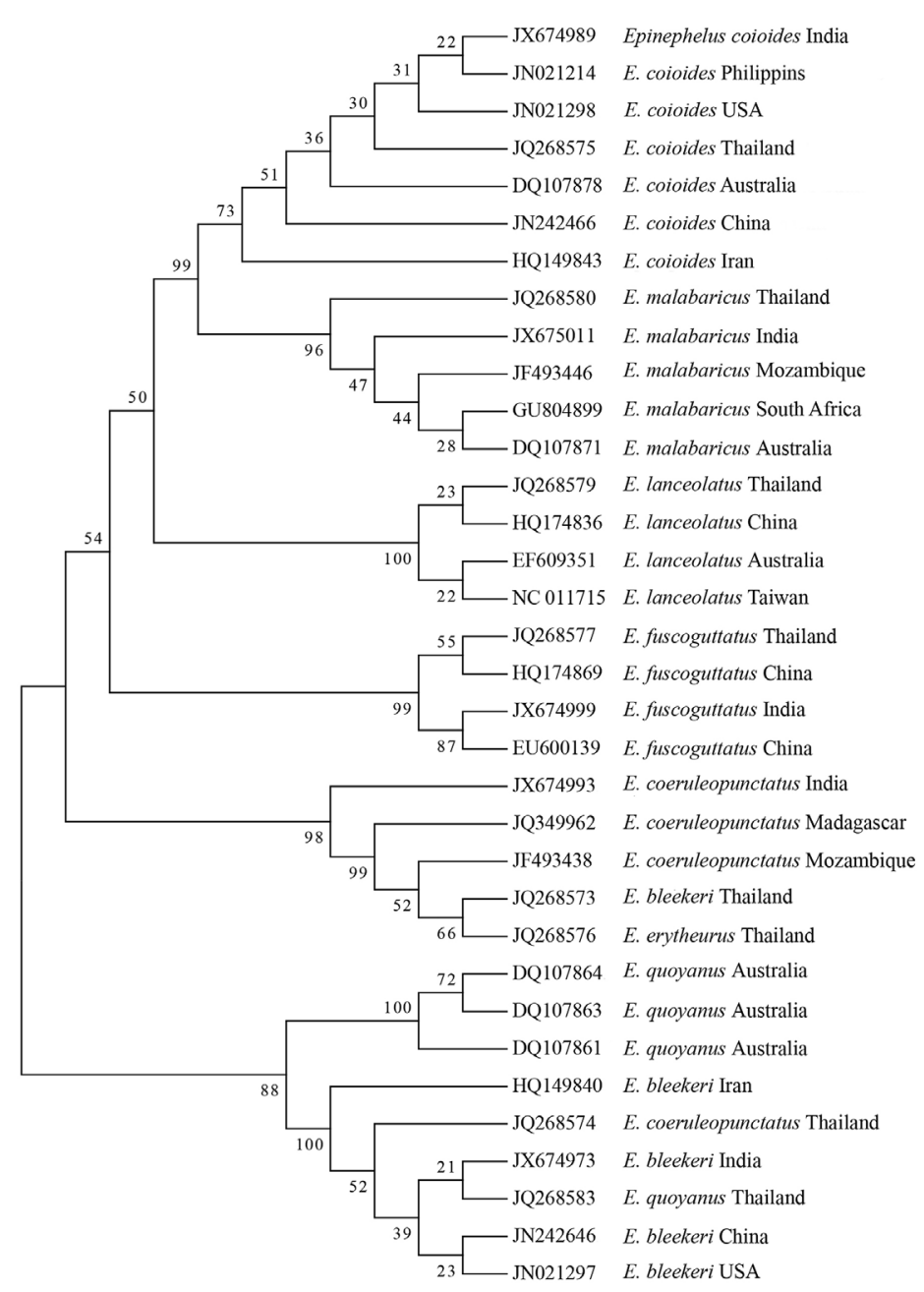

Figure 6. Dendrogram resulting from the MEGA5 analysis of Epinephelus species from Thailand and other countries based on MT-CO1sequence data. Bootstrap values are presented on the branches.

The MT-RNR2 sequences of two species, E. bleekeri from India and E. malabaricus from Thailand and India, do not support the hypothesis that it is a monophyletic species group. Epinephelus bleekeri from India is separated from its species group and remains in a monophyletic group with $E$. malabaricus from India; in addition, E. malabaricus from India is separated out from its species group, and E. malabaricus from Thailand clusters with E. coioides. The first barcode sequence of Thai E. erythrurus is very similar to that of Thai $E$. coeruleopunctatus (Figure 5). In addition, the MT-CO1 sequences of three species, E. bleekeri, E. quoyanus, and E. coeruleopunctatus indicate divergence from their species groups; E. bleekeri from each country are distinguished from each other except for the species from China and the USA; E. quoyanus from Thailand are separated from those from Australia; and E. coeruleopunctatus of Thailand are also separated from its species group (Figure 6). 


\section{DISCUSSION}

The study of Epinephelus species diversity in Thailand is far from complete. We attempted to find specimens for two years, but only eight species were found. This may be because these fishes inhabit deep water in the open sea, making them difficult to capture. Morphological characters can be efficiently used for species identification. However, characters can vary depending on the life stage of the fish, and variation can occur in characters, such as size or colors and patterns, which can be rapidly altered when the fish is stressed or the environment has changed. Therefore, molecular markers should be used for consistent species identification, and RAPD markers are a powerful tool for differentiating species as shown by the dendrogram and similarity indices in Table 1 . This method has more advantages than using solely morphological characters for species identification, including the investigation of the genome and examining expressed and unexpressed characters. Additionally, each band is equivalent to a character and as a large number of bands were used in this study, this provides greater confidence in the results. The cladogram (Figure 2) separated each pair of species, aggregated individuals of the same species and separated the ingroup from the outgroup, which demonstrates the resolution of RAPD data. Intraspecific S values, which ranged from 0.65 to 0.99 , overlapped with the interspecific $S$ values of 0.23 to 0.66 . However, each pair of the same species has a common ancestor and is monophyletic, which is the same principle as different species that do not have a common ancestor being a polyphyletic group. The $\mathrm{S}$ value $0.65-0.66$ of different species, $E$. coeruleopunctatus and E. erythrurus, may be caused by correlated or specifically convergence genetic characters that not distinguished by the RAPD analysis.

Because all Epinephelus species are economically profitable when sold as food, there needs to be specific markers that allow rapid, automated, and accurate species identification, especially for the juveniles that are common in coastal fish farming. Additionally, these markers could be used for the identification of incomplete specimens, extinct species, individual species at different life stages and cryptic species. This DNA barcoding has served this purpose. Therefore, after morphological identification, the species-specific barcodes were compiled to support the previously mentioned evidence. DNA barcoding using MT-RNR2 and MT-CO1 was performed for each species following the guidelines set by Ivanova et al. (2007) and Zhang and Hanner (2011). They proposed that these gene regions be used as standard barcoding markers for fishes, including the marine fishes from Japan. Waugh (2007) suggested that mitochondrial DNA (mtDNA) offers several advantages over nuclear DNA. Therefore, mtDNA is preferable for use as a barcode capable of differentiating species.

The genetic distances of barcode values in MT-RNR2 (0.037-0.159) and MT-CO1 (0.003-0.157) from eight species of Epinephelus from Thailand can be used for rapid, accurate, and automated identification in cases of incomplete or morphologically ambiguous specimens, following the barcode concept. When compared, barcode sequences from Thailand and those from other countries can be used for identification based on the levels of nucleotide variation; individuals that are determined by morphology to be members of the same species, are usually monophyletic. However, some morphologically defined species do not form monophyletic clades. E. bleekeri from India and E. malabaricus from Thailand and India, are not monophyletic according to the MT-RNR2 data. Furthermore, E. bleekeri, E. quoyanus, and E. coeruleopunctatus are not monophyletic according to the MT-CO1 data, as shown in Figure 4. Variations occur in MT-RNR2 region can be located in any of the nucleotide sites. Whereas, the variations in 
MT-CO1 region occur in the third nucleotide site of the amino acid codon, and so the same gene sequence variation can occur in different species. Because of this, barcodes from many gene regions should be used, or a standardized region for a particular group of species.

The sequences of E. lanceolatus from each country are highly conserved, with the intraspecific genetic distances ranging from 0.000 to 0.003 . Another important result from this research is that the barcode sequence from Thai E. erythrurus was previously absent from the GenBank and is presented here for the first time.

\section{REFERENCES}

Banasopit T (1968). Handbook of the Groupers (Serranidae) of the Thai Waters. Marine Fisheries Laboratory, Division of Research and Investigations, Department of Fisheries, Bangkok.

Bardakci F and Skibinski DO (1994). Application of the RAPD technique in tilapia fish: species and subspecies identification. Heredity 73: 117-123.

Bielawski JP and Pumo DE (1997). Randomly amplified polymorphic DNA (RAPD) analysis of Atlantic Coast striped bass. Heredity 78: 32-40.

Callejas C and Ochando MD (2001). Molecular identification (RAPD) of the eight species of the genus Barbus (Cyprinidae) in the Iberian Peninsula. J. Fish Biol. 59: 1589-1599.

Dice LR (1945). Measures of the amount of ecological association between species. Ecology 26: 297-302.

Duangsawasdi M (1964). A Study on the Groupers (Epinephelidae) in Thai Waters. Bachelor Thesis in Fisheries, Faculty of Fisheries, Kasetsart University, Bangkok.

Froese R and Pauly D (2012). FishBase World Wide Web Electronic Publication. Available at [www.fishbase.org]. Accessed June 1, 2012.

Govindaraju GS and Jayasankar P (2004). Taxonomic relationship among seven species of groupers (genus Epinephelus; family Serranidae) as revealed by RAPD fingerprinting. Mar. Biotechnol. 6: 229-237.

Hebert PDN, Stoeckle MY, Zemlak TS and Francis CM (2004). Identification of birds through DNA barcodes. PLoS Biol. 2: $1657-1663$.

Heemstra PC and Randall JE (1993). FAO Species Catalogue. Vol. 16. Groupers of the World (Family Serranidae, Subfamily Epinephelinae). An Annotated and Illustrated Catalogue of the Grouper, Rockcod, Hind, Coral Grouper and lyretail Species Known to Date. FAO Fisheries Synopsis, Rome.

Ivanova NV, Zemlak TS, Hanner RH and Hebert PDN (2007). Universal primer cocktails for fish DNA barcoding. Mol. Ecol. Notes 7: 544-548.

Jayasankar P (2004). Random amplified polymorphic DNA (RAPD) fingerprinting resolves species ambiguity of domesticated clown fish (genus: Amphiprion, family: Pomacentridae) from India. Aquac. Res. 35: 1006-1009.

Koedprang W, Na-Nakorn U, Nakajima M and Taniguchi N (2007). Evaluation of genetic diversity of eight grouper species Epinephelus spp. based on microsatellite variations. Fish. Sci. 73: 227-236.

Lakra WS, Verma MS, Goswami M, Lal KK, et al. (2011). DNA barcoding Indian marine fishes. Mol. Ecol. Resour. 11: 60-71.

NCBI (2013). The Basic Local Alignment Search Tool (BLAST), National Center for Biotechnology Information (NCBI). Available at [http://blast.ncbi.nlm.nih.gov/Blast.cgi]. Accessed January 7, 2013.

Rohlf FJ (1998). NTSYSpc: Numerical Taxonomy and Multivariate Analysis System Version 2.1. Applied Biostatistics Inc., New York.

Rutherford K, Parkhill J, Crook J, Horsnell T, et al. (2000). Artemis: sequence visualization and annotation. Bioinformatics 16: 944-945.

Sachithanandam V, Mohan PM, Muruganandam N, Chaaithanya IK, et al. (2012). DNA barcoding, phylogenetic study of Epinephelus spp. From Andaman coastal region, India. Indian J. Mar. Sci. 41: 203-211.

Sneath PH and Sokal RR (1973). Numerical Taxonomy. W. H. Freeman \& Co., San Francisco.

Suvatti C (1950). Fauna of Thailand. Department of Fisheries, Bangkok.

Tamura K, Peterson D, Peterson N, Stecher G, et al. (2011). MEGA5: molecular evolutionary genetics analysis using maximum likelihood, evolutionary distance, and maximum parsimony methods. Mol. Biol. Evol. 28: 2731-2739.

Ward RD, Holmes BH and Yearsley GK (2008). DNA barcoding reveals a likely second species of Asian sea bass (barramundi) (Lates calcarifer). J. Fish Biol. 72: 458-463.

Waugh J (2007). DNA barcoding in animal species: progress, potential and pitfalls. Bioessays 29: 188-197.

Zhang JB and Hanner R (2011). DNA barcoding is a useful tool for the identification of marine fishes. Biochem. Syst. Ecol. 39: 31-42. 
Zhang JB and Hanner R (2012). Molecular approach to the identification of fish in the South China Sea. PLoS One 7: e30621. Available at [http://www.plosone.org/article/info\%3Adoi\%2F10.1371\%2Fjournal.pone.0030621]. Accessed November 22, 2012. 